\title{
6th San Luis Conference on Surfaces, Interfaces and Catalysis
}

\author{
J. Anibal Boscoboinik ${ }^{1} \cdot$ Florencia C. Calaza ${ }^{2}$. Octavio J. Furlong ${ }^{3} \cdot$ Sebastián E. Collins ${ }^{2}$
}

Published online: 20 September 2019

(c) Springer Science+Business Media, LLC, part of Springer Nature 2019

The present Issue of Topics in Catalysis contains selected contributions from participants of the 6th San Luis Conference and School on Surfaces, Interfaces and Catalysis, which took place in Santa Fe, Argentina, from June 2nd to June 8th, 2018. This was the sixth in a series of meetings aiming to unite Latin American, US and European scientists in the areas of surface chemistry, with particular emphasis on heterogeneous catalysis. A Humboldt Kolleg took place before the Conference and as part of the School. The event was organized by J. Anibal Boscoboinik (CFN, BNL, USA), Florencia C. Calaza (INTEC, CONICET-UNL, Argentina) and Octavio J. Furlong (INFAP, CONICET-UNSL, Argentina), together with Sebastian E. Collins (INTEC, CONICET-UNL, Argentina) acting as main coordinator of all organization activities in the city of Santa Fe.

The San Luis conference series started in 1994, as a celebration of the 400th anniversary of the founding of San Luis city (Argentina). At that moment, Professors Francisco Zaera (UCR, Riverside, CA), Eddy Tysoe (UWM, Milwaukee, WI) and Giorgio Zgrablich (UNSL, San Luis) organized the first meeting, financed primarily by the San Luis Province, with additional funds from the Argentine National Government. This event brought together theorists and experimentalists from the area of surface science, mostly related to catalysis, with the main purpose of exposing Argentine students to leading international scientists from the Americas and Europe. Its outcome greatly exceeded the organizers expectations, resulting in several new collaborative projects between Argentine universities and foreign

Florencia C. Calaza

fcalaza@intec.unl.edu.ar

1 Brookhaven National Laboratory, Center for Functional Nanomaterials, Upton, NY, USA

2 Instituto de Desarrollo Tecnológico para la Industria Química (CONICET-CONICET), Santa Fe, Argentina

3 INFAP/CONICET, Universidad Nacional de San Luis, San Luis, Argentina institutions. A special issue including work presented in the conference was published in the journal Langmuir.

By the second and third San Luis Symposiums, the former held in Mar del Plata, Argentina, in 2000, and the latter in Merida, Venezuela, in 2004, both funded primarily by US National Science Foundation (NSF), a Summer School on Surface Science was implemented. Fellowships were given to a few US graduate students with the intention of fostering collaborations with people early in their professional careers. There was a substantial increase in international participation, with people attending from the United States, Mexico, Venezuela, Brazil, Argentina, the United Kingdom, France, Italy and Japan. New collaborations were established, and the proceedings were published in The Journal of Molecular Catalysis A: Chemical in both instances.

A Fourth San Luis Summer School and Symposium on Surfaces, Interfaces and Catalysis was held in Cuernavaca, Mexico, in 2007, with 120 attendees (compared to around 70 attendees in previous meetings) from 15 countries, with a total of 39 oral presentations and 93 posters, presented in three separate sessions. The proceedings were again published in a special issue of The Journal of Molecular Catalysis: Chemical. At this point, and given the increasing success of these meetings, the main organizers and original founders of the San Luis Symposium decided to continue the series as a periodic event with locations that will rotate among the different Latin American countries. With that in mind, the fifth chapter was held in São Pedro, Brazil, in 2010. This conference was financed primarily by US-NSF under their PASI program, but additional funding was secured from the Universidade Federale de São Carlos, and from private companies. Once again, the meeting proved to be highly successful in terms of number of attendees, participation, quality of presentations and new collaborations being fostered. A selection of works presented at the Conference was published in the journal Topics in Catalysis.

After the sad passing of Prof. Giorgio Zgrablich in 2012, the San Luis Conference remained dormant for some years, until a group of young researchers that had attended previous instances and whose careers had benefitted form these 
events, decided to organize the Sixth San Luis Conference and Summer School in Santa Fe, Argentina. For that, the following Committees were assembled:

General Organizing Committee:

- Dr. Anibal Boscoboinik (BNL, Long Island, USA)

- Dr. Florencia Calaza, INTEC (CONICET-UNL, Argentina)

- Dr. Octavio J. Furlong, INFAP (CONICET-UNSL, Argentina)

Local Organizing Committee:

- Dr. Sebastian Collins, INTEC (Coordinator)

- Dr. Marta V. Bosco, INTEC

- Dr. Florencia Calaza, INTEC

- Dr. Lucila Cristina, IFIS-Litoral

- Dr. Esteban Fornero, INTEC

- Dr. Mario Passeggi (h), IFIS-Litoral

- Dr. Gustavo Ruano, IFIS-Litoral

- Dr. Ana Tarditi, INCAPE

- Dr. Julia Vecchietti, INTEC

\section{Scientific Committee:}

- Dr. Hendrik Bluhm (LBL, Berkeley, USA)

- Dr. Anibal Boscoboinik (BNL, Long Island, USA)

- Prof. Hans-Joachim Freund (FHI, Berlin, Germany)

- Prof. William Kaden (UCF, Orlando, USA)

- Prof. Gianfranco Pacchioni (Univ. Milan, Italy)

- Dr. Paola Quaino (IQAL-UNL, Santa Fe, Argentina)

- Dr. Dario Stacchiola (BNL, Long Island, USA)

- Dr. Fernando Stavale (CBPF, Rio de Janeiro, Brazil)

- Prof. Eddy Tysoe (UWM, Milwaukee, USA)

- Prof. Francisco Zaera (UCR, Riverside, USA)

The Conference was preceded by a 4-day School on Surfaces Interfaces and Catalysis (June 2-5), with lectures given by international and local experts covering some of the basic concepts that would then be expanded during the conference presentations. This arrangement allowed the speakers to provide a background for their talks, while allowing students to interact and ask questions in a more comfortable environment. As part of the School, during June 4-5, a Humboldt Kolleg was organized by Humboldtians J. Anibal Boscobonik (CFN-BNL, USA), Florencia Calaza (INTEC, Argentina), William Kaden (UCF, USA) and Fernando Stavale (CBPF, Brazil). In this setting, besides the planned academic lectures given primarily by Humboldtians to the students, several more social interactions took place, where the students could obtain informal feedback and information about the programs offered by the Alexander von Humboldt Foundation. During the first day of the Kolleg, a special session celebrating the 40th anniversary of INCAPE was held, and in the morning of second day, a session in honor of Giorgio Zgrablich took place, with presentations mainly from Theory and Modeling fields. A total number of 57 students and 21 invited lecturers participated during the School, with participants coming from Spain, United States, Germany, Austria, Mexico, Switzerland, Argentina and Brazil. In the last day of the School, all students presenting posters during the Conference were given the opportunity to briefly show, in a poster-slam format, the most important findings from their posters. A total of 26 students (out of 57 applicants) received financial support to attend the School and Conference, helping to cover their travel and accommodation expenses. This was possible thanks to the funds from the Argentine National Scientific and Technical Research Council (CONICET), the Alexander von Humboldt Foundation, the Ministry of Science, Technology and Productive Innovation of Santa Fe, and several local and international companies.

The conference itself was held during June $6-8$, and consisted of a series of invited and contributed talks and two poster sessions. In total, during the 3 days of Conference, 128 researchers participated, with 14 plenary lectures, 21 contributed oral presentations and 93 posters showcased. It is important to remark the high quality and originality of results presented, with high percentage of unpublished work presented by researchers. For readers interested in more details about the Conference, we redirect them to the following link https://servicios.intec.santafe-conicet.gov.ar/ eventos/sanluisvi. Overall, the VI San Luis Conference and School on Surfaces, Interfaces and Catalysis showed high success, and is being regarded as a perfect setting for international exchange of ideas and research in the field of surface science, with special emphasis on heterogeneous catalysis, providing an excellent format for collaborations between Latin American researchers with worldwide colleagues. The comments collected from all attendees were extremely positive, with most of them asking when and where the next Conference instance will take place. The General Committee is greatly thankful to everyone who made this VI SLC such a great success, and is looking forward to prepare for the next chapter in the near future.

For the present volume, selected works showcased by participants and invited speakers, were compiled in a total of 25 written contributions. The fundamental physico-chemical aspects of the surface chemistry involved during catalytic processes are the interconnection of all contributions, ranging from theoretical modeling studies, experimental work from high surface area related fields to surface science highly ordered systems, and modern approaches using Operando techniques to bridge the gaps between these fields. We hope you enjoy reading this special issue and become 
interested in participating in future San Luis Conference chapters if you have not done so already.

We want to further acknowledge and express our sincere thanks to the administrative staff from INTEC (CONICETUNL), who provided their time and logistics help making all participants feel comfortable during the meeting. Also, very special thanks go to the staff of Topics in Catalysis for providing precise support and technical assistance during the preparation and publication processes, in particular to Dr. Charlotte Hollingworth, Mr. Matthew Smyllie and their group of assistants. We are greatly thankful to Professor Hajo Freund for the opportunity given to present the community with this special issue and his continuous support for keeping alive the San Luis Conference series, and finally we are grateful to all authors and reviewers who contributed with their time and efforts to make this possible.

Publisher's Note Springer Nature remains neutral with regard to jurisdictional claims in published maps and institutional affiliations. 